\title{
The Statistical Evolution of Multiple Generations of Oxidation Products in the Photochemical Aging of Chemically Reduced Organic Aerosol
}

\author{
Kevin R. Wilson, ${ }^{1, *}$ Jared D. Smith, ${ }^{1}$ Sean Kessler ${ }^{2}$ and Jesse H. Kroll ${ }^{2,3}$ \\ ${ }^{1}$ Chemical Sciences Division, Lawrence Berkeley National Laboratory, Berkeley, CA 94720 \\ ${ }^{2}$ Department of Chemical Engineering, Massachusetts Institute of Technology, Cambridge, MA 02139 \\ ${ }^{3}$ Department of Civil and Environmental Engineering, Massachusetts Institute of Technology, Cambridge, \\ MA 02139
}

\begin{abstract}
The heterogeneous reaction of hydroxyl radicals $(\mathrm{OH})$ with squalane and bis(2-ethylhexyl) sebacate (BES) particles are used as model systems to examine how distributions of reaction products evolve during the oxidation of chemically reduced organic aerosol. A kinetic model of multigenerational chemistry, which is compared to previously measured (squalane) and new (BES) experimental data, reveals that it is the statistical mixtures of different generations of oxidation products that control the average particle mass and elemental composition during the reaction. The model suggests that more highly oxidized reaction products, although initially formed with low probability, play a large role in the production of gas phase reaction products. In general, these results highlight the importance of considering atmospheric oxidation as a statistical process, further suggesting that the underlying distribution of molecules could play important roles in aerosol formation as well as in the evolution of key physicochemical properties such as volatility and hygroscopicity.

* Correspondence to K.R. Wilson (krwilson@lbl.gov)
\end{abstract}




\section{Introduction}

Understanding the various photochemical pathways by which organic aerosol (OA) forms and evolves in the atmosphere is critical for accurately predicting and assessing the impact of aerosols on human health and on climate. A key challenge is to develop robust general theories or parameterizations of aerosol formation and aging that can accurately describe the chemical transformations of hundreds, if not thousands, of distinct molecular species found in ambient aerosols or are gas phase precursors for their formation. ${ }^{1}$ Such parameterizations include a number of recently-developed "reduced" variable representations of organic aerosol formation and aging, ${ }^{2-7}$ which are based upon measureable average bulk aerosol properties, such as elemental ratios $(\mathrm{O} / \mathrm{C}$ and $\mathrm{H} / \mathrm{C}),{ }^{3}$ carbon oxidation state, ${ }^{5}$ polarity, ${ }^{6}$ volatility, ${ }^{2}{ }^{7}$ or electron ionization marker ions ${ }^{8}$ to represent how oxidation changes organic aerosol composition.

Although such parameterizations hold the promise of improved modeling of the loadings and properties of OA, by reducing the immense chemical complexity of OA into simpler, more computationally tractable descriptions, a key challenge remains in accurately understanding the kinetics, oxidation chemistry and statistical evolution of reaction products within these spaces. It has been shown that the formation and evolution of OA often occurs in several steps by the formation of products that have undergone multiple oxidation reactions (i.e. generations), which impact the loadings and properties of the aerosol, a process generally termed as "aging". 4, 8-9 As a consequence, photochemical aging may form complex mixtures of product generations each with distinct chemical and physical properties, which may not be resolved by ensemble-based measurements or model frameworks that characterize aerosol solely via average properties. 
Multigenerational oxidation in the formation or evolution of OA proceeds via a set of fundamental processes that can be broadly classified as oligomerization, functionalization and fragmentation. $^{4-5,10}$ Functionalization is the addition of oxygenated functional groups to either an existing organic aerosol or gas phase precursor. This produces distributions of oxidation products that decrease the average aerosol volatility, by increasing the average molecular weight and polarity of molecular constituents leading to SOA formation or an increase in particle hygroscopicity.

Alternatively, fragmentation forms oxidation products by cleaving carbon-carbon bonds yielding smaller molecular weight molecules with higher vapor pressures than the functionalization pathway. For secondary organic aerosol formation, fragmentation reactions are directly observed by detecting specific reaction products $^{11-12}$ or inferred by the analysis of aerosol yield, ${ }^{12} \mathrm{O} / \mathrm{C}$ or volatility measurements. ${ }^{9,}{ }^{13}$ In heterogeneous oxidation, fragmentation is detected if one or both of the molecular fragments evaporate leading to detectable changes in particle mass - a process often termed volatilization. There are a number of studies that report the decrease in particle size upon oxidation, as well as the formation of both particle-phase ${ }^{14-15}$ and gas phase ${ }^{16}$ scission products. Although the largest yield of gas phase reaction products appear to be small molecules such as formic acid, ${ }^{16-17}$ there is evidence for the formation of larger aldehydes, ketones, and carboxylic acids with sizable carbon chain lengths (up to $\mathrm{C}_{13}$ ). ${ }^{16}$

Two model heterogeneous reactions $(\mathrm{OH}+$ squalane and $\mathrm{OH}+$ bis(2-ethylhexyl sebacate, BES) will be analyzed to show that the competition between fragmentation and functionalization can be described by the formation, volatilization and subsequent statistical evolution of the underlying oxidation products within the aerosol. The experimental measurements of the squalane reaction have been previously reported, ${ }^{10,18-19}$, while the kinetic 
measurements of BES presented here are new. This main objective of this work is to present a new framework to reveal how distributions of molecules control ensemble averaged aerosol properties. Examining oxidation within these simplified model aerosol systems allows a detailed investigation of how chemical complexity evolves from a single hydrocarbon species to an aerosol whose properties are increasingly governed by multiple generations of oxidation products. This framework, although formulated to explain simple heterogeneous reactions, reveals more broadly the importance of developing statistical approaches for connecting average bulk aerosol properties with the underlying distribution of individual reaction products. Such statistically-based approaches might even have utility in understanding or even predicting how average organic aerosol properties evolve chemically in the atmosphere.

\section{Previous Results: Squalane $+\mathbf{O H}$}

In previous publications, our laboratory has examined the kinetics and mechanisms of the heterogeneous oxidation of squalane $(\mathrm{Sq})$, a branched alkane $\left(\mathrm{C}_{30} \mathrm{H}_{62}\right)$, by the $\mathrm{OH}$ radical (with $\left.\mathrm{O}_{2}\right) .{ }^{10,18-19}$ As reported in Smith et al., ${ }^{19}$ the formation of multiple generations of oxidation products, denoted simply as $\mathrm{SqO}_{\mathrm{n}}$, where $\mathrm{n}$ equals the number of oxygenated functional groups added to the original squalane molecule, was observed using vacuum ultraviolet photoionization (VUV) aerosol mass spectrometry. It was found that the formation of these oxidation products, in the presence of $\mathrm{O}_{2}$, is statistical, and well-described by a sequential oxidation mechanism in which a single oxygenated functional group per molecule is added per reactive collision of $\mathrm{OH}$ with the particle surface. Shown in Fig. 1 is the previously measured ${ }^{19}$ kinetic evolution of these squalane oxidation products $\left(\mathrm{SqO}_{\mathrm{n}}\right)$ as a function of $\mathrm{OH}$ exposure. Detailed analysis of the kinetic evolution of $\mathrm{SqO}_{n}$ revealed that the distribution of products, $f(n,[O H] t)$, at any point in the reaction could be expressed as a Poisson distribution, 


$$
f(n,[O H] \cdot t)=\frac{\left[S q O_{n}\right]([O H] \cdot t)}{[S q]_{0}}=\frac{(k[O H] t)^{n}}{n !} e^{(-k[O H] t)}
$$

where $[\mathrm{Sq}]_{0}$ is the initial molecular density $\left(\right.$ molec. $\mathrm{cm}^{-3}$ ) of squalane, and $[\mathrm{OH}]^{\bullet} \mathrm{t}$ is exposure (molec. $\left.\mathrm{cm}^{-3} \mathrm{~s}\right) . \quad k$ is the second order rate coefficient $\left(\mathrm{cm}^{3}\right.$ molec $\left.^{-1} \mathrm{~s}^{-1}\right)$ for the reaction and is related to the reactive uptake coefficient $(\gamma)$ by,

$$
k=\frac{\gamma \bar{c} 6 M}{4 D_{S} \rho N_{A}}
$$

where $\rho$ is average particle density, $\mathrm{N}_{\mathrm{A}}$ is Avogadro's number, $\bar{c}$ mean speed of $\mathrm{OH}, \mathrm{M}$ is the average molar mass and $D_{s}$ surface-weighted particle diameter of the log-normal particle size distribution used in the experiment. The average generation number or expectation value of the distribution shown in Eq. (1) is $<\mathrm{n}>=k[\mathrm{OH}] \mathrm{t}$, which is also the kinetic lifetime of squalane. ${ }^{10,19}$ At low $\mathrm{OH}$ exposures the uptake coefficient for the reaction was measured to be $\gamma=0.26$ (not corrected for $\mathrm{OH}$ diffusion) and within measurement error was found to be the same for the various oxidation products (i.e. $\mathrm{Sq}, \mathrm{SqO}, \mathrm{SqO}_{2}$ and $\left.\mathrm{SqO}_{3}\right) .{ }^{19}$

It should be pointed out that the above statistical treatment of multigenerational kinetics is applicable to systems (individual particles or even air masses) that are internally well-mixed on the timescale of a reaction, so that each individual molecule has an equal probability for reacting with $\mathrm{OH}$. For aerosols with diffusive limitations (e.g. "glasses" or solids) a more complex representation of the kinetics would be needed for the case where the mixing time is much slower than the rate of chemical transformation in the atmosphere.

A discrete representation of the distribution of oxidation products from the $\mathrm{Sq}+\mathrm{OH} / \mathrm{O}_{2}$ reaction is computed using Eq. (1) and shown in Fig. 2. Within any product generation there can be many distinct molecular structures containing alcohol or carbonyl functional groups, as reported by a number of previous studies. ${ }^{15,20-21}$ A detailed investigation of the functional groups 
that are formed within a specific product generation can yield additional insights into the microscopic chemical mechanism, but for the work presented here we consider only the total number of oxygen functional groups per generation.

Before reaction the particle consists of a single component, squalane (Sq), whose generation number $\mathrm{n}=0$ (Fig. 2a). Upon reaction, squalane is consumed, producing a distribution of oxidation products, which evolves toward larger $<\mathrm{n}>$, as shown for two different $\mathrm{OH}$ exposures in Fig. 2. The average generation number of the distributions shown in Figs. $2 \mathrm{~b}$ and $\mathrm{c}$ is 2.7 and 7.2, respectively. As $\mathrm{OH}$ exposure is increased, the number of product generations increase producing a broad distribution of oxidation products with generation numbers distributed above and below $<\mathrm{n}>$. These results show in some detail how photochemical aging functionalizes a particle by forming distributions of reaction products during a heterogeneous reaction.

In a second study, reported in Kroll et al., ${ }^{10}$ the squalane aerosol is exposed to much larger $[\mathrm{OH}]$ (up to 35 squalane kinetic lifetimes) to further investigate how the average aerosol properties evolve over many product generations in order to more closely examine fragmentation (i.e. "volatilization") pathways. Measurements of average particle properties, such as aerosol mass, density, $\mathrm{H} / \mathrm{C}$ and $\mathrm{O} / \mathrm{C}$ ratios, revealed that beyond 2-3 squalane kinetic lifetimes, carbon loss from the particle becomes an increasingly important reaction pathway, ultimately playing a considerable role in increasing the carbon oxidation state of the particle. ${ }^{5}$

The probability of carbon loss upon oxidation was shown to increase monotonically but non-linearly as the aerosol becomes increasingly oxidized, reaching $\sim 100 \%$ when the $\mathrm{O} / \mathrm{C}$ ratio of the OA exceeds $\sim 0.3 .^{10}$ This suggests that volatilization is enhanced as a molecule becomes increasingly functionalized. Qualitatively similar results were observed recently by Mysak et 
al. $^{22}$ for the heterogeneous oxidation of coronene thin films by both $\mathrm{OH}$ and ozone. More generally, these results suggest that oxidation reactions of more oxygenated organic aerosol (e.g. SOA) preferentially lose carbon and/or oxygen as gas phase reaction products. Our recent observations of substantial volatilization arising from the heterogeneous reactions of $\mathrm{OH}$ with oxygenated compounds, erythritol $(\mathrm{O} / \mathrm{C}=1)$ and levoglucosan $(\mathrm{O} / \mathrm{C}=0.83)$, also supports this conclusion. ${ }^{23}$

These previous studies, which examine the dependence of volatilization/fragmentation on

parameters such as $\mathrm{O} / \mathrm{C},{ }^{19,23}$ focus only on the relationship between the observed chemistry and the average properties of the OA. They do not directly address how different generations of oxidation products (shown in Figs. 1 and 2) co-present in the OA, might exhibit different reactivities (such as likelihood for volatilization). The aim of the present work is to examine the link between the molecular evolution of oxidation products ${ }^{19}$ and the chemical transformation of the average aerosol mass and elemental composition, ${ }^{10}$ in order to better understand how different generations of oxidation may influence the key ensemble properties (loading, volatility, hygroscopicity, etc.) of organic aerosol.

To do this, a description of multigenerational kinetics described by Eq. (1) (and illustrated in Fig. 2) will be combined with a simple parameterization of the key chemical properties of individual reaction products as a function of generation number. This parameterization, termed a volatilization operator, is described in the following section, followed by modeling results.

\section{Model Formulation}

Our model of multigenerational heterogeneous oxidation considers only a single particle size and is parameterized with the average surface-weighted particle diameter $\left(\mathrm{D}_{\mathrm{s}}=160 \mathrm{~nm}\right)$ of 
the log normal distribution (geometric standard deviation $\sim 1.3$ ) of particle sizes used in the experiment. Eq. (1) is used to compute the distribution of oxidation products in the particle at any point in the reaction (e.g. functionalization). It is assumed that over the course of the reaction that the particle remains well-mixed, so that oxidation occurs uniformly throughout the particle and the distribution of oxidation products can be described by the Poisson distribution shown in Eq. (1).

The computed product distributions, illustrated in Fig. 2, connect the molecular evolution of the squalane reaction products with the average measured aerosol mass and elemental composition (e.g. oxygen-to-carbon ratios). Each component of the distribution (e.g. $\mathrm{SqO}_{\mathrm{n}}$ ) is characterized in terms of its key molecular properties: density, molecular weight, $\mathrm{O} / \mathrm{C}, \mathrm{H} / \mathrm{C}$, etc. The contribution of each molecular species to each average aerosol property is proportional to the probability of forming that product at any point in the reaction. Further details of the these properties are given below.

Oxygen Atom Content. A highly simplified reaction scheme is used to describe the formation of oxidation products $\left(\mathrm{SqO}_{\mathrm{n}}\right)$ within the aerosol upon a heterogeneous reaction. It is assumed, based upon previous measurements, ${ }^{19,} 24$ that 1 oxygen functional group is added to a molecule per heterogeneous reaction, and thus each product generation, $n$, contains n number of oxygen atoms. When volatilization/fragmentation is neglected, the $\mathrm{O} / \mathrm{C}$ ratio of product, $\mathrm{SqO}_{\mathrm{n}}$, is $\mathrm{n} / 30$. The average $\mathrm{O} / \mathrm{C}$ ratio of the particle can then be computed from the underlying population of the individual oxidation products $\left(\mathrm{SqO}_{\mathrm{n}}\right)$. For example, for the distributions shown in Fig. 2b and $\mathrm{c}$, the average product numbers are $<\mathrm{n}>$ is 2.7 and 7.2 ; corresponding to an average $\mathrm{O} / \mathrm{C}$ ratio of 0.09 and 0.24 , respectively (again, neglecting volatilization which will be considered below). 
Hydrogen Atom Content. The change in the number of hydrogen atoms per reaction is not wellconstrained by the data, and is highly dependent on the detailed chemical mechanism. If the oxidation reaction produces exclusively carbonyl functional groups, then each product generation (n) differs from the previous one (n-1) by the addition of 1 oxygen atom and the loss of 2 hydrogen atoms. If instead the reaction produces only alcohol functional groups then every product in the distribution would have the same number of $\mathrm{H}$ atoms as squalane (i.e. 62). If alcohol and carbonyl functional groups are produced in equal quantities, consistent with the condensed phase Russell Mechanism, ${ }^{25}$ then on average one $\mathrm{H}$ atom would be lost per reaction. Thus the number of hydrogen atoms lost per generation is constrained to be between 0 (alcohol) and 2 (carbonyl), and is left as an adjustable parameter in the model.

It is found that an average loss of 1.5 hydrogen atoms per generation (n) yields the best overall representation of the changes in aerosol elemental composition over the broad range of $\mathrm{OH}$ exposures considered here. This is also consistent with the results of Smith and coworkers ${ }^{21}$ who observed the enrichment of ketones relative to alcohols in the heterogeneous oxidation of BES, suggesting that alternative pathways for the $\mathrm{RO}_{2}$ self reaction (i.e. Bennett-Summers mechanism ${ }^{26}$ ) might be important. Shown in Fig. $3 \mathrm{a}$ is the measured $\mathrm{H} / \mathrm{C}$ ratio plotted as a function of $\mathrm{O} / \mathrm{C}$, in a "Van Krevelen diagram." As discussed by previously, ${ }^{3,23}$ oxidation represented in this space can provide a measure of the average evolution of the kinds of functional groups produced during the reaction. The reaction begins at squalane $(\mathrm{H} / \mathrm{C}=2.0$ and $\mathrm{O} / \mathrm{C}=0$ ), and upon oxidation the $\mathrm{H} / \mathrm{C}$ decreases with increasing $\mathrm{O} / \mathrm{C}$. The data in Fig. 3a show that at early stages of the reaction $(\mathrm{O} / \mathrm{C}<0.15)$ the slope is -2.2 and decreases to -0.76 at $\mathrm{O} / \mathrm{C}>$ 0.2. This suggests that the exact distribution of functional groups is in fact evolving during the reaction, which is not explicitly accounted for in the model presented here. However as shown in 
Fig. 3a, using an average of 1 oxygen atom added and a loss of 1.5 hydrogen atoms per generation (n) does yield a reasonable representation of how the average experimentally measured compositional changes in the aerosol evolve over the entire range of $\mathrm{OH}$ exposures examined here.

Density: As reported by Kroll et al., ${ }^{10}$ the average particle density of the squalane increases with oxidation. This is consistent with the difference between the density of a reduced organic and one that is more highly oxygenated. The density of each oxidation product, $\mathrm{SqO}_{\mathrm{n}}$, is parameterized to increase with product number (n) to reflect the changes in density that naturally occur upon the addition of oxygenated functional groups to an un-functionalized alkane such as squalane. The average density of the particle $(\rho)$ at any point in the reaction is computed by taking the density of each product generation weighted by its fractional contribution to the particle. To best represent the global data set for the squalane reaction, the density of each generation $\left(\rho_{\mathrm{n}}\right)$ is parameterized to increase linearly as a function of product number $\mathrm{n}$ according to,

$$
{ }_{n}=0.03 \cdot n+0.81
$$

For example, $\mathrm{Sq}(\mathrm{n}=0)$ has a density of $0.81 \mathrm{~g} \mathrm{~cm}^{-3}$ compared with $\mathrm{SqO}_{4}$, which is parameterized in the model, according the Eq. (3), to have a density of $0.93 \mathrm{~g} \mathrm{~cm}^{-3}$, which is reasonably consistent the density of a long chain ester BES $\left(\mathrm{C}_{26} \mathrm{H}_{50} \mathrm{O}_{4}\right)$ whose density is $0.92 \mathrm{~g} \mathrm{~cm}^{-3} \cdot{ }^{20}$ It should be pointed out that the rate coefficient $(k)$ in Eq. (2) depends upon the average particle density $(\rho)$ as well as diameter $\left(D_{s}\right)$, and molar mass $(M)$. These quantities all evolve during oxidation, and are updated in the model at every point in the reaction.

Volatilization/fragmentation branching ratio: Finally, a "volatilization" operator is used in the model to describe the effects of fragmentation reactions, which cause some fraction of the mass 
(oxygen, carbon and hydrogen atoms) associated with each product generation to leave the particle as gas-phase reaction products. For simplicity the model does not explicitly consider how material is lost from the particle which could occur in the form of small gas phase molecules (e.g. $\mathrm{CO}_{2}$ ) or the re-partitioning of larger semi-volatile fragmentation (i.e. scission) products. Additionally it is assumed that no additional oxygen is added to either the particle- or gas-phase molecule during fragmentation.

The probability for decomposition into gas phase products is assumed to increase with product number, which is consistent with a number of recent observations that volatilization increases with oxidation, ${ }^{10,23}$ due to the increasing probability that an $\mathrm{OH}$ reaction will occur on or adjacent to an existing oxygenated functional group or at a tertiary carbon site. ${ }^{10}$ Reactions at these sites could open up a variety of reaction pathways and possibly the formation of alkoxy radical intermediates, which can lead to $\mathrm{C}-\mathrm{C}$ bond scission reactions and molecular decomposition. $^{11,17,27}$

Thus, it is expected that the probability for volatilization is larger for a species such as $\mathrm{SqO}_{15}$ relative to an oxidation product with only a single functional group (i.e. SqO). To yield the best representation of the data described below, the volatilization operator, $\beta(\mathrm{n})$, is assumed to be a function of product number (n) and is parameterized as follows,

$$
\begin{array}{cc}
\beta(n)=0 & (n=0-2) \\
\beta(n)=(\alpha \cdot n-0.12) & (3 \leq n \leq 26) \\
\beta(n)=1 \quad(n>26)
\end{array}
$$

where $\alpha$ is an adjustable coefficient in the model. For oxidation products with only 1 or 2 oxygenated functional groups the volatilization operator is assumed to be 0 , indicating that these products do not volatilize but rather remain in the particle, fully contributing to the computed 
average particle phase properties (i.e. mass, elemental composition, etc.). For products $n=3$ and higher (the model extends to $\mathrm{n}=26$ ), the volatilization operator is assumed for simplicity to be linear function of $n$. This transition from no volatilization at $n=1-2$ (Eq. (4a)), to the onset of volatilization at $\mathrm{n}=3$, represented by the non-zero intercept of 0.12 in Eq. $4 \mathrm{~b}$, reflects the expectation that there should be some threshold or minimum number of oxygenated functional groups attached to the squalane molecule before there is an appreciable probability for volatilization. To best represent the observed loss of particulate mass during the heterogeneous oxidation of squalane, $\alpha$ is fixed at 0.0432 . For example, $\beta(15)=0.528$ for $\mathrm{SqO}_{15}$ indicating that $53 \%$ of the carbon, oxygen and hydrogen atoms associated with this product generation volatilizes as gas phase products. For $\mathrm{n}>26$, the atomic constituents of these reaction products fully volatilize and do not contribute to the average particle phase mass or elemental composition. A graphical representation of the volatilization operator as a function of generation number is shown in Fig. 2d.

In summary, the contribution in the model of any particular product generation to the average aerosol properties $(\mathrm{O} / \mathrm{C}, \mathrm{H} / \mathrm{C}$, mass, density, etc.) is governed both by its statistical probability of formation (Eq. (1)), which evolves with $\mathrm{OH}$ exposure and by the volatilization operator described by Eq. (4) and shown in Fig. 2d, which is a static function of product number, n.

\section{Results}

\section{a. Squalane $+\mathbf{O H}$}

Shown as solid lines in Figs. 1, 3, 4, 6 and 8 are model calculations, as parameterized above to include both functionalization (Eq. (1)) and volatilization (Eq. (4)), compared with the experimental observations. To reproduce the full data set, the uptake coefficient is allowed to 
monotonically decrease during the reaction in proportion to the number of hydrogen atoms remaining in the particle. This is consistent with the expectation that as the reaction proceeds there is an overall depletion in the average number of $\mathrm{C}-\mathrm{H}$ bonds as they are replaced with oxygenated function groups such are carbonyls, which might have very different heterogeneous reactivity.

The average density and volume vs. $\mathrm{OH}$ exposure is computed by taking the ensemble averages of each oxidation product $n$, whose density is parameterized via Eq. (3). The computed density and volume (normalized to unreacted squalane) accurately represent the measured values as shown in Fig. $3 \mathrm{~b}$ and reported in Kroll et al. ${ }^{10}$

Shown in Fig. 4 are measurements of normalized average aerosol mass and the $\mathrm{O} / \mathrm{C}$ ratio for the squalane $+\mathrm{OH}$ reaction, previously reported in Kroll et al. ${ }^{10}$ At the beginning of the reaction the aerosol mass (Fig. 4a) and $\mathrm{O} / \mathrm{C}$ ratio (Fig. 4b) increase with $\mathrm{OH}$ exposure. The increase in both the $\mathrm{O} / \mathrm{C}$ ratio and aerosol mass in this region can be explained solely by the incorporation of oxygen atoms into the aerosol particle. This is illustrated with dashed lines in Figs. $4 \mathrm{a}$ and $\mathrm{b}$, which are predictions of the aerosol mass and O/C computed using only Eq. (1) and neglecting volatilization (i.e. Eq. (4)). Overall, at low $\mathrm{OH}$ exposures the agreement between the measurements and Eq. (1) (no volatilization) is good, indicating that the increase in aerosol mass and $\mathrm{O} / \mathrm{C}$ is controlled by the formation of new oxygenated functional groups (functionalization) in the particle.

However at larger $\mathrm{OH}$ exposures $\left(\sim 1.4 \times 10^{12} \mathrm{molec}^{-3} \mathrm{~s}\right)$ the measured aerosol mass decreases and deviates from Eq. (1), which shows the growing importance of the volatilization pathway that results in chemical loss of material from the particle. In a similar way, the measurements of $\mathrm{O} / \mathrm{C}$ increasingly deviate from Eq. (1), although at later stages in the reaction 
( $\mathrm{OH}$ exposures of $\sim 4 \times 10^{12}$ molec $\mathrm{cm}^{-3} \mathrm{~s}$ ) relative to the aerosol mass, thus providing additional evidence that the chemical transformation of the aerosol is not governed solely by the simple addition of oxygenated functional groups. It should be noted that the measured aerosol mass deviates from the predictions of Eq. (1) at average bulk $\mathrm{O} / \mathrm{C}$ ratio between $0.05-0.09$, indicating that gas phase reaction products are formed when on average there are very few (1.5-2.7) oxygenated functional groups added to the original squalane molecule. Similar observations ${ }^{20}$ of the "early" onset of volatilization of a chemically reduced aerosol have been noted by various authors examining heterogeneous reactions of $\mathrm{OH}$ with other model aerosol, such as palmitic $\operatorname{acid}^{15}$ and BES. ${ }^{20}$

The deviation of the predictions of Eq. (1) from the measured aerosol mass and $\mathrm{O} / \mathrm{C}$ ratio at different points in the reaction ( $\mathrm{OH}$ exposures) confirms that volatilization (Eq. (4)) may be preferentially occurring from more highly oxidized reaction products located at the tail end of the product distribution (e.g. $\mathrm{SqO}_{10}$ in Fig. 2). This is because the average $\mathrm{O} / \mathrm{C}$ is sensitive to the number-weighted distribution of individual oxidation products, while the average aerosol mass is sensitive to changes in those molecules or generations that have the largest molecular weight. Later generations of more oxidized products (e.g. $\mathrm{SqO}_{10}$ ) are statistically insignificant in number during the early stages of oxidation and therefore contribute little to the average $\mathrm{O} / \mathrm{C}$ ratio of the particle. However, any changes (volatilization) in these later generations of products can disproportionately influence the average aerosol mass since these generations have larger molecular weights, which simply reflect the differences between the number- and mass-weighted distributions of product generations.

The model including the volatilization operator captures the increase in aerosol mass early in the reaction where the probability for volatilization is small since the evolution of 
aerosol mass is mainly controlled by the formation of early generations of molecular products (n $=0-3$ ) whose kinetic evolution is shown in Fig. 1. As shown in Fig. 5, the total aerosol mass can be sub-divided into contributions of various generations of oxidation products. As the reaction progresses the full model including volatilization captures the non-monotonic evolution of aerosol mass, correctly replicating the turn over at $\sim 2 \times 10^{12}$ molec. $\mathrm{cm}^{-3} \mathrm{~s}$ followed by the decrease in aerosol mass at larger $\mathrm{OH}$ exposures. As shown in Fig. 5, this is the point in the reaction where later generation of oxidation products $(n=3-8)$, (which have some probability for volatilization), begin to increasingly contribute to the average aerosol mass. By late in the reaction, early generations of oxidation products have been consumed by $\mathrm{OH}$ and the changes in normalized aerosol mass are dominated by the formation and subsequent volatilization of higher generations of reaction products (i.e. $\mathrm{n}=9-20$ ) as shown in Fig. 5. This illustrates how changes in average aerosol mass at any point in the reaction are controlled by the properties of many generations of oxidation products.

As shown in Fig. 4, the increase in the $\mathrm{O} / \mathrm{C}$ ratio over the entire reaction is also correctly represented by the model using Eq. (1) and the volatilization operator (Eq. (4)), showing the eventual plateau in elemental composition at larger exposures. Also shown in Fig. 4 is the predicted average $\mathrm{O} / \mathrm{C}$ ratio of the gas phase products formed during volatilization, which closely mirrors the evolution of particle phase $\mathrm{O} / \mathrm{C}$ with $\mathrm{OH}$ exposure. Within the assumption that there are no additional oxygenated functional groups are added during fragmentation, the model predicts that over the course of the reaction, the $\mathrm{O} / \mathrm{C}$ ratio of the gas phase reaction products produced by volatilization is always larger than the elemental composition of the particle phase. This occurs because the gas phase elemental composition originates from the volatilization of the more oxidized particle phase constituents, which over most of the reaction contribute little to the 
average $\mathrm{O} / \mathrm{C}$ of the aerosol itself. In reality, this difference may even be larger than that, due to the additional incorporation of $\mathrm{O}$ atoms from fragmentation, not captured in the model.

Shown in Fig. 6 is the average numbers of $\mathrm{C}, \mathrm{H}$, and $\mathrm{O}$ atoms compared with experimental measurements reported in Kroll et al. ${ }^{10}$ The model correctly replicates the increase in the average number of oxygen atoms, which eventually plateaus when $\mathrm{OH}$ exposures are $\sim 1 \mathrm{x}$ $10^{13}$ molec $\mathrm{cm}^{-3} \mathrm{~s}$. The model also correctly exhibits the narrow region at the beginning of the reaction where the number of carbon atoms remains constant (pure functionalization), followed by a decrease in the average carbon content are larger $\mathrm{OH}$ exposures. Finally, the decrease in the average number of hydrogen atoms by more than a factor of 2 is reproduced by the model, indicating that the assumption that each product generation (n) loses 1.5 hydrogen atoms per oxidation step is indeed reasonable.

Shown in Fig. 7 is the modeled generational contribution to the changes in the average number carbon and oxygen atoms in the aerosol during the reaction. At early stages in reaction, generations 1-5 contribute most to the increase in the average number of oxygen atoms in the particle. The nearly constant number of average carbon atoms at the start of the reactions merely reflects that these generations, which dominate the composition of the aerosol at small $\mathrm{OH}$ exposures, have small probabilities of volatilization. At later stages in the reaction the average number of carbon and oxygen atoms are controlled by larger generation numbers, which have increased probabilities for volatilization, leading to an overall decrease in the average number of carbons in the particle and a plateau of the particle phase oxygen content.

To summarize how the evolution of the underlying distribution of oxidation products influence fragmentation/volatilization and functionalization in the multigenerational oxidation of squalane, the measured and modeled elemental composition can be used to formulate the 
heterogeneous oxidation trajectory shown in Fig. 8. This particular "reduced variable representation" is intended to show how the average number of oxygen and carbon atoms in the aerosol, which arises from underlying distribution of oxidation products, changes as oxidation proceeds. This is done by plotting the net number of oxygen atoms added during the reaction vs. the amount of carbon lost (Fig. 6). Overall the measured trajectory can be represented by a linear combination of three of the idealized vectors, discussed previously by Mysak et al. ${ }^{22}$ and shown in Fig. 9. At early stages of the reaction functionalization dominates, producing a vector with a vertical slope. This is the point in the reaction where the particle is primarily composed of early generations of oxidation products $(n<4)$ whose overall volatilization probability is parameterized to be small. Later on in the reaction the trajectory exhibits a positive slope as more oxygenated higher molecular weight products $(n>6)$ populate the tail end of the distribution. These products have a larger probability for volatilization, which both leads to some carbon loss and the slower rate of net oxygen addition thus producing a vector with a positive slope. Near the end of the reaction, the slope of the trajectory becomes zero, indicating that the rate of oxygen addition, controlled mainly by the early product generations, is balanced by the volatilization (loss of oxygen and carbon) of oxidation products at the tail end of the distribution. Although not experimentally measured for the squalane reaction, the model trajectory if extended to larger exposures would eventually become negative, indicating that the photochemical evolution of the aerosol is entirely dominated by the decomposition of oxidation products at the tail end of the distribution. This has been observed recently for $\mathrm{OH}$ and $\mathrm{O}_{3}+$ coronene reaction as well as for the heterogeneous oxidation of levoglucosan and eyrthritol. ${ }^{23}$ In general, this multigenerational analysis of the various slopes that are present in the heterogeneous oxidation trajectory of squalane (Figs. 8 and 9) illustrate in some detail how the 
distribution and evolution of products can control the oxidative evolution of OA shown in "reduced variable" representations of photochemical aging.

\section{b. bis(2-ethylhexyl) sebacate $+\mathrm{OH}$}

Although the model correctly predicts both the average and molecular evolution of squalane during its heterogeneous reaction with $\mathrm{OH}$, a further application of the kinetic framework presented here is conducted for a slightly more oxygenated model aerosol system comprised of bis(2-ethylhexyl) sebacate. The kinetics of the reaction of BES with $\mathrm{OH}$ (in the presence of $\mathrm{O}_{2}$ ) are measured for a log-normal particle size distribution with a surface-weighted diameter of $120 \mathrm{~nm}$. A $10.5 \mathrm{eV}$ VUV aerosol mass spectrum, recorded during the reaction is shown in Fig. 10 The experimental approach and methods used to measure this heterogeneous reaction are described in detail in Smith et al. ${ }^{19}$ As observed for the squalane reaction, a set of oxidation products are formed and separated by $\Delta \mathrm{m} / \mathrm{z}=14-16$. The product peaks are labeled by the number of oxygenated functional groups--BES, $\mathrm{BESO}, \mathrm{BESO}_{2}$ and $\mathrm{BESO}_{3}$. These oxidation products, as shown already by a number of authors, correspond to the formation of alcohol and carbonyl functional groups. $^{20-21}$ Shown in Fig. 11 is the kinetic evolution of these oxidation products as a function of $\mathrm{OH}$ exposure. The overall kinetic evolution of the particle is nearly identical to what was previously observed for squalane by Smith et al. ${ }^{19}$ and Liu et al. ${ }^{24}$ The oxidation products evolve consecutively, and are well represented by Eq. (1) using an uptake coefficient of $0.5 \pm 0.07$ (not corrected for $\mathrm{OH}$ diffusion) and by assuming that 1 oxygenated functional group is added per reaction. The uptake coefficient determined here is somewhat smaller than previous measurements, which are corrected for $\mathrm{OH}$ diffusion. George et al. ${ }^{20}$ reported $\gamma=1.3$ from an initial fit of their BES decay data, while Hearn et al. ${ }^{28}$ measured $\gamma=2.0$ for the $\mathrm{OH}$ oxidation of BES. The reason for this discrepancy is currently unclear, but for a self 
consistent presentation of the model results, $\gamma=0.5$ is used throughout the subsequent analysis detailed below.

Shown in Fig. 12 are measurements of the average mass, density and volume normalized to unreacted BES as reported by George et al., ${ }^{20}$ for the reaction of $\mathrm{OH}$ with $150 \mathrm{~nm}$ sizeselected BES particles. Shown in Fig. 12 are model results parameterized with $\gamma=0.5$, and assuming that 1 oxygen atom is added per generation (n) with an average loss of $1.5 \mathrm{H}$ atoms per reaction, as described above for squalane. As with squalane, the density of each BES reaction product is parameterized to evolve linearly with $n$ with a slope of 0.5 from the known density of $\operatorname{BES}\left(0.92 \mathrm{~g} \mathrm{~cm}^{-3}\right)$. The volatilization operator for BES is found to be,

$$
\begin{gathered}
\beta(n)=0 \quad(n=0-3) \\
\beta(n)=(\alpha \cdot n-0.15) \quad(4 \leq n \leq 25) \\
\beta(n)=1 \quad(n>25)
\end{gathered}
$$

where the coefficient $(\alpha)$ that best represents the data is found to be $\alpha=0.047$. These parameters yield the reasonable representation of both the kinetic evolution of oxidation products shown in Fig. 11 and the changes in density and aerosol mass with $\mathrm{OH}$ exposure reported by George et al. $^{20}$ and shown in Fig. 12.

Shown in Fig. 13 is the measured $\mathrm{O} / \mathrm{C}$ ratio for BES vs. $\mathrm{OH}$ exposure reported in Lambe et al. ${ }^{29}$ Here a linear offset of +0.1138 is applied to the $\mathrm{O} / \mathrm{C}$ data reported in Lambe et al., ${ }^{29}$ so that the correct atomic ratio for un-reacted BES is obtained to facilitate an easier comparison with the model results presented here. As shown in Fig. 13, the model correctly replicates the linear increase in the $\mathrm{O} / \mathrm{C}$ ratio with $\mathrm{OH}$ exposure observed in the experiment. The range of $\mathrm{OH}$ exposures for BES reaction is much smaller than that for the squalane data set described above. 
The Van Krevelen representation of this reaction is shown in Fig. 14, using the H/C ratio also reported in Lambe et al. ${ }^{29}$ The model replicates the evolution of this reaction in Van Krevelen space (H/C vs. O/C) with a modeled average slope of -1.5 . Unfortunately, the data set for the $\mathrm{BES}+\mathrm{OH}$ reaction is more limited than for squalane, preventing further tests and refinements of the model parameters. Nevertheless, the conceptual framework, originally developed to understand the multigenerational oxidation of squalane, appears quite suitable for understanding both kinetic evolution of individual oxidation products as well as the changes in average aerosol mass and elemental composition.

\section{Discussion}

The heterogeneous transformation of the two chemically reduced model systems considered here, can be described by considering the statistical evolution of oxidation products and an empirical volatilization operator, which is parameterized above according to product number, $\mathrm{n}$. In both systems, functionalization is found to occur statistically via the sequential addition of 1 oxygenated functional group per reactive collision as determined by examining the molecular evolution of oxidation products detected using VUV photoionization aerosol mass spectrometry.

To further examine the chemical meaning of the empirical volatilization operators used to replicate the experimental data, the operator can be transformed from a function of product number, $n$, to a more chemically meaningful quantity — such as $\mathrm{O} / \mathrm{C}$ ratio or average carbon oxidation $\operatorname{state}^{5}\left(\overline{O s_{C}}\right)$ of generation, $\mathrm{n}$. This allows closer inspection of the differences and/or similarities between these two heterogeneous reactions as shown in Fig. 15. Plotting the volatilization operator vs. the $\mathrm{O} / \mathrm{C}$ ratio of each product generation (Fig. 15) shows that although the BES and squalane functions have similar slopes, the absolute magnitude of $\beta(\mathrm{O} / \mathrm{C})$ differs 
significantly for both reactions. For the BES oxidation product that has an $\mathrm{O} / \mathrm{C}$ ratio of 0.5 , $\beta(\mathrm{O} / \mathrm{C})=0.27$, which is quite different than $\beta(\mathrm{O} / \mathrm{C})=0.53$ for the squalane product with the same $\mathrm{O} / \mathrm{C}$ ratio.

Average carbon oxidation state $\left(\overline{O s_{C}}\right)$ is another metric for oxidation and is related to the elemental ratios via,

$$
\overline{O s_{C}} \approx 2 \frac{O}{C}-\frac{H}{C}
$$

as recently described in Kroll et al. ${ }^{5}$ Shown in Fig. 15 is the volatilization operator recast as a function of the absolute change in average carbon oxidation state $\left(\Delta \overline{O s_{C}}\right)$ of a product generation, $\mathrm{n}$, relative to that of pure squalane or BES. For example, squalane has an average carbon oxidation state of -2 , while its first oxidation product in the model $(\mathrm{SqO}=\mathrm{Sq}+1 \mathrm{O}-1.5 \mathrm{H})$ has an average oxidation state of -1.95 . So for product $\mathrm{n}=1$, the absolute change in carbon oxidation state is $\Delta \overline{O s_{C}}=\left|\overline{O s_{C}}(S q O)-\overline{O s_{C}}(S q)\right|=0.05$. As shown in Fig. 15, despite differences in the volatilization operator as a function of $\mathrm{n}$ or $\mathrm{O} / \mathrm{C}$ for Sq and BES, the operator expressed in terms of $\Delta \overline{O s_{C}}$ yields a somewhat consistent representation for both heterogeneous reactions. For both systems small changes in average carbon oxidation state of a generation produce small probabilities for volatilization, while larger changes relative to pure squalane or BES increase the likelihood of volatilization.

There are a number of possible implications of expressing the volatilization operator as a function of $\Delta \overline{O s_{C}}$. First, it is clear that considering only the absolute average carbon oxidation state (as opposed to the change to the average carbon oxidation state) of a particular molecule may not adequately represent its propensity for fragmentation or volatilization during oxidation. This is because there are many stable molecules that have average carbon oxidation states or $\mathrm{O} / \mathrm{C}$ ratios that are similar to some of the oxidation products shown here, which are parameterized to 
volatilize. For example, in the model, $\mathrm{SqO}_{13}$, which undergoes volatilization, has an average oxidation state of -0.5 and an $\mathrm{O} / \mathrm{C}$ ratio of 0.43 , compared with a hydrocarbon such as coronene, which has a similar oxidation state but an $\mathrm{O} / \mathrm{C}$ ratio of zero.

Second, for the long chain hydrocarbons considered here, the average carbon oxidation state can be changed in small increments by the sequential addition of 1 oxygen atom (and the loss of $1.5 \mathrm{H}$ atoms) to the $\mathrm{C}_{30}$ carbon skeleton. This is in contrast with molecules that have smaller carbon chain lengths, since the addition of a single oxygen functional group can lead to a larger incremental change in average carbon oxidation state and therefore propensity for volatilization. For example, the heterogeneous oxidation of smaller more oxygenated molecules, such as erythritol $\left(\mathrm{C}_{4} \mathrm{H}_{10} \mathrm{O}_{4}\right)$ and levoglucosan $\left(\mathrm{C}_{6} \mathrm{H}_{10} \mathrm{O}_{5}\right)$, produced substantial volatilization. ${ }^{23}$ In a future publication, we will consider the statistical evolution and volatilization of oxidation products for a much larger array of chemically reduced as well as oxidized organic aerosols to examine the general applicability and meaning of the empirical volatilization operator presented here.

The linear volatilization operator can be compared with a hypothetical parameterization presented in Jimenez et al., ${ }^{4}$ where it is assumed that fragmentation scales as $\mathrm{O} / \mathrm{C}^{1 / 6}$. With that parameterization, a compound with an $\mathrm{O} / \mathrm{C}$ of 0.5 yields a $90 \%$ chance of fragmentation. The linear volatilization operator reported here exhibits a much different relationship as a function of $\mathrm{O} / \mathrm{C}$, but some care should be exercised in comparing these two parameterizations, since fragmentation of a molecule does not necessarily lead to its volatilization. It is possible that fragmentation could produce daughter molecules that still contain enough oxygen so that they remain in the particle phase, which would not lead to detectable changes in aerosol mass but rather only in particle volatility. The measurements and model framework presented here would 
be insensitive to this case. In fact George et al. ${ }^{20}$ and McNeill et al., ${ }^{15}$ detected some smaller molecular weight products remaining in the particle phase arising from the $\mathrm{OH}$ oxidation of BES and palmitic acid, respectively.

Alternative hypothetical parameterizations have also been considered by us in order to replicate the experimental results presented here. As an alternative to the linear volatilization operator used here, an operator was constructed based upon the probability that an $\mathrm{OH}$ reaction occurs adjacent to an existing functional group. This approach would produce a nonlinear function with a volatilization probability near 1 for an $\mathrm{O} / \mathrm{C}$ of 0.5 in the case of squalane. Unfortunately, this function would over predict the amount of volatilization that is observed in the experiment, suggesting that more complex interactions than the reactive site distribution are controlling the amount of heterogeneous volatilization observed in these systems.

Although the molecular identity of the gas phase products is not explicitly considered here, a limited number of previous gas phase $\mathrm{e}^{10,16-17}$ and thermodenuder measurements ${ }^{10}$ suggest that they could be small oxygenated molecules. Further studies are needed to precisely measure the gas phase evolution of the reaction products formed during the heterogeneous reaction. The gas phase products should be formed with a recognizable kinetic pattern (as a function of $\mathrm{OH}$ exposure) that is correlated with the consecutive evolution of the condensed phase oxidation products shown in Fig. 1. Further detailed studies are clearly needed to elucidate the mechanism by which oxidation breaks C-C bonds.

It should be pointed out that the non-linear relationship between the average branching ratio for carbon loss vs. $\mathrm{O} / \mathrm{C}$ reported in Kroll et al., ${ }^{10}$ which is computed by taking the derivative of the average number of $\mathrm{C}$ and $\mathrm{O}$ atoms in the particle (Fig. 6), is faithfully reproduced using the model parameterizations reported here (not shown). This would then indicate that there may 
be some difficulty in predicting the volatilization probability of individual molecules solely from average elemental measurements (i.e. carbon loss vs. O/C) of bulk aerosol properties. In other words, the non-linear dependence of the average branching ratio for carbon loss reported in

Kroll et al., ${ }^{10}$ is captured using Eq. (1) and a linear volatilization operator for the distribution of individual oxidation products (e.g. $\mathrm{SqO}_{\mathrm{n}}$ ) within the particle. This is a particularly important for understanding why there is an "early" onset of volatilization for squalane and BES at such small average $\mathrm{O} / \mathrm{C}$ ratios $(\sim 0.07)$. This "early" onset of volatilization is not governed by average $<\mathrm{n}>$ or $\mathrm{O} / \mathrm{C}$ but rather by generations of more oxygenated molecules located at tail of the distribution (with $\mathrm{O} / \mathrm{C}$ ratios $>0.2$ ). This clearly illustrates the importance of considering the formation and evolution of statistical populations of multiple generations of oxidation underlying any measured average aerosol property such as volatility, $\mathrm{O} / \mathrm{C}$ ratio or even hygroscopicity. In a future publication we will explicitly investigate how multiple generations of oxidation control the evolution of the average cloud condensation nuclei activity of photochemically aged squalane and BES.

\section{Conclusion}

We have presented a kinetic framework that describes the photochemical evolution of chemically reduced organic aerosol exposed to $\mathrm{OH}$ radicals in the presence of $\mathrm{O}_{2}$. This model attempts to connect the underlying molecular evolution of oxidation products with the transformation of average aerosol properties such as mass, $\mathrm{O} / \mathrm{C}$, etc. To do this, an empirical volatilization operator is introduced, which allows the individual molecular constituents in the multi-component particle to undergo volatilization according to their degree of oxidation relative to the parent compound (Sq or BES.) When volatilization (via fragmentation reactions) is included, the model replicates all of the available experimental observations for the squalane and 
$\mathrm{BES}+\mathrm{OH}$ reaction and shows that photochemical aging of chemically reduced OA proceeds via both functionalization and volatilization. It is now clear for the squalane reaction that it is the underlying statistical distribution of reaction products that control its oxidative "movement" within reduced variable representations of aerosol aging, which are based upon average carbon oxidation state, ${ }^{5}$ mass spectral ion markers or elemental ratios. ${ }^{3}$

The framework of multi-generation heterogeneous oxidation presented here, explores only one dimension in the complex photochemical evolution of OA. Other critical dimensions, for example, include understanding the interplay between average $\mathrm{O} / \mathrm{C}$ and the distribution of volatilities $^{2,7,30}$ (e.g. Volatility Basis Set) or hygroscopicities necessary for modeling either the formation of secondary organic aerosol or its cloud condensation nuclei $(\mathrm{CCN})$ activity. To explicitly include how oxidation changes average aerosol volatility or hygroscopicity into the general framework described here, requires a more complete picture of the distribution of functional groups within a single product generation ${ }^{31}$ or an understanding of how solubility changes with generation number.

The results presented here, although formulated for model heterogeneous reactions, suggest more broadly the importance of considering atmospheric oxidation as a statistical mixture of products from multiple oxidation generations. The use of Eqs. (1) and (4) to predict the distribution of oxidation products is not limited solely to heterogeneous reactions, and could also be applied to the development of new statistically-based descriptions of secondary organic aerosol formation. For this case, one could imagine considering statistical distributions of average carbon oxidation states within a complex multi-component aerosol rather than considering chemistry solely within an individual molecule-based framework. Furthermore, in many gas to particle formation reactions, it is the higher generations of reaction products that 
partition to the aerosol phase, which are also the species that might have the highest probability of fragmentation. While it is clearly important to understand molecular reaction pathways for organic aerosol formation and evolution, the enormous complexity of ambient aerosols, comprised of thousands of compounds, suggests the need for the development of new statistically-based, computationally efficient treatments of multi-generational oxidation chemistry as described here.

Acknowledgments: This work was supported by the Director, Office of Energy Research, Office of Basic Energy Sciences, Chemical Sciences Division of the U.S. Department of Energy under Contract No. DE-AC02-05CH11231.

\section{References}

1. A. H. Goldstein and I. E. Galbally, Environ. Sci. Technol., 2007, 41, 1514-1521.

2. N. M. Donahue, S. A. Epstein, S. N. Pandis and A. L. Robinson, Atmos. Chem. Phys., 2011, 11, 3303-3318.

3. C. L. Heald, J. H. Kroll, J. L. Jimenez, K. S. Docherty, P. F. DeCarlo, A. C. Aiken, Q. Chen, S. T. Martin, D. K. Farmer and P. Artaxo, Geophys. Res. Lett., 2010, 37.

4. J. L. Jimenez, M. R. Canagaratna, N. M. Donahue, A. S. H. Prevot, Q. Zhang, J. H. Kroll, P. F. DeCarlo, J. D. Allan, H. Coe, N. L. Ng, A. C. Aiken, K. S. Docherty, I. M. Ulbrich, A. P. Grieshop, A. L. Robinson, J. Duplissy, J. D. Smith, K. R. Wilson, V. A. Lanz, C. Hueglin, Y. L. Sun, J. Tian, A. Laaksonen, T. Raatikainen, J. Rautiainen, P. Vaattovaara, M. Ehn, M. Kulmala, J. M. Tomlinson, D. R. Collins, M. J. Cubison, E. J. Dunlea, J. A. Huffman, T. B. Onasch, M. R. Alfarra, P. I. Williams, K. Bower, Y. Kondo, J. Schneider, F. Drewnick, S. Borrmann, S. Weimer, K. Demerjian, D. Salcedo, L. Cottrell, R. Griffin, A. Takami, T. Miyoshi, S. Hatakeyama, A. Shimono, J. Y. Sun, Y. M. Zhang, K. Dzepina, J. R. Kimmel, D. Sueper, J. T. Jayne, S. C. Herndon, A. M. Trimborn, L. R. 
Williams, E. C. Wood, A. M. Middlebrook, C. E. Kolb, U. Baltensperger and D. R. Worsnop, Science, 2009, 326, 1525-1529.

5. J. H. Kroll, N. M. Donahue, J. L. Jimenez, S. H. Kessler, M. R. Canagaratna, K. R. Wilson, K. E. Altieri, L. R. Mazzoleni, A. S. Wozniak, H. Bluhm, E. R. Mysak, J. D. Smith, C. E. Kolb and D. R. Worsnop, Nature Chemistry, 2011, 3, 133-139.

6. J. F. Pankow and K. C. Barsanti, Atmospheric Environment, 2009, 43, 2829-2835.

7. N. M. Donahue, A. L. Robinson, C. O. Stanier and S. N. Pandis, Environ. Sci. Technol., 2006, 40, 2635-2643.

8. N. L. Ng, M. R. Canagaratna, Q. Zhang, J. L. Jimenez, J. Tian, I. M. Ulbrich, J. H. Kroll, K. S. Docherty, P. S. Chhabra, R. Bahreini, S. M. Murphy, J. H. Seinfeld, L. Hildebrandt, N. M. Donahue, P. F. DeCarlo, V. A. Lanz, A. S. H. Prevot, E. Dinar, Y. Rudich and D. R. Worsnop, Atmos. Chem. Phys., 2010, 10, 4625-4641.

9. A. L. Robinson, N. M. Donahue and W. F. Rogge, Journal of Geophysical ResearchAtmospheres, 2006, 111.

10. J. H. Kroll, J. D. Smith, D. L. Che, S. H. Kessler, D. R. Worsnop and K. R. Wilson, Physical Chemistry Chemical Physics, 2009, 11, 8005-8014.

11. H. J. Chacon-Madrid, A. A. Presto and N. M. Donahue, Physical Chemistry Chemical Physics, 2010, 12, 13975-13982.

12. Y. B. Lim and P. J. Ziemann, Aerosol Science and Technology, 2009, 43, 604-619.

13. A. A. Presto, M. A. Miracolo, J. H. Kroll, D. R. Worsnop, A. L. Robinson and N. M. Donahue, Environ. Sci. Technol., 2009, 43, 4744-4749.

14. I. J. George, R. Y. W. Chang, V. Danov, A. Vlasenko and J. P. D. Abbatt, Atmospheric Environment, 2009, 43, 5038-5045.

15. V. F. McNeill, R. L. N. Yatavelli, J. A. Thornton, C. B. Stipe and O. Landgrebe, Atmos. Chem. Phys., 2008, 8, 5465-5476.

16. A. Vlasenko, I. J. George and J. P. D. Abbatt, Journal of Physical Chemistry A, 2008, 112, 1552-1560.

17. M. J. Molina, A. V. Ivanov, S. Trakhtenberg and L. T. Molina, Geophys. Res. Lett., 2004, 31.

18. D. L. Che, J. D. Smith, S. R. Leone, M. Ahmed and K. R. Wilson, Physical Chemistry Chemical Physics, 2009, 11, 7885-7895. 
19. J. D. Smith, J. H. Kroll, C. D. Cappa, D. L. Che, C. L. Liu, M. Ahmed, S. R. Leone, D. R. Worsnop and K. R. Wilson, Atmos. Chem. Phys., 2009, 9, 3209-3222.

20. I. J. George, A. Vlasenko, J. G. Slowik, K. Broekhuizen and J. P. D. Abbatt, Atmos. Chem. Phys., 2007, 7, 4187-4201.

21. J. D. Hearn, L. H. Renbaum, X. Wang and G. D. Smith, Physical Chemistry Chemical Physics, 2007, 9, 4803-4813.

22. E. R. Mysak, J. D. Smith, P. D. Ashby, J. T. Newberg, K. R. Wilson and H. Bluhm, Physical Chemistry Chemical Physics, 2011, 13, 7554-7564.

23. S. H. Kessler, J. D. Smith, D. L. Che, D. R. Worsnop, K. R. Wilson and J. H. Kroll, Environ. Sci. Technol., 2010, 44, 7005-7010.

24. C. L. Liu, J. D. Smith, D. L. Che, M. Ahmed, S. R. Leone and K. R. Wilson, Physical Chemistry Chemical Physics, 2011, 13, 8993-9007.

25. G. A. Russell, Journal of the American Chemical Society, 1957, 79, 3871-3877.

26. J. E. Bennett and R. Summers, Canadian Journal of Chemistry-Revue Canadienne De Chimie, 1974, 52, 1377-1379.

27. R. Atkinson, International Journal of Chemical Kinetics, 1997, 29, 99-111.

28. J. D. Hearn and G. D. Smith, Geophys. Res. Lett., 2006, 33.

29. A. T. Lambe, A. T. Ahern, L. R. Williams, J. G. Slowik, J. P. S. Wong, J. P. D. Abbatt, W. H. Brune, N. L. Ng, J. P. Wright, D. R. Croasdale, D. R. Worsnop, P. Davidovits and T. B. Onasch, Atmos. Meas. Tech., 2011, 4, 445-461.

30. J. F. Pankow, Atmospheric Environment, 1994, 28, 185-188.

31. S. H. Kessler, T. Nah, A. Carrasquillo, J. T. Jayne, D. R. Worsnop, K. R. Wilson and J. H. Kroll, Journal of Physical Chemistry Letters, 2011, 2, 1295-1300. 


\section{Figure Captions}

Figure 1: (a-d) The experimentally measured ( $($ ) evolution of squalane oxidation products $\left(\mathrm{SqO}_{\mathrm{n}}\right)$ as a function of $\mathrm{OH}$ exposure $([\mathrm{OH}] \mathrm{t})$. Data is originally reported in Smith et al. ${ }^{19}$ Each oxidation product is labeled according to the number (n) of oxygenated function groups. For unreacted squalane $\mathrm{n}=0$. Solid lines are model calculations.

Figure 2: Computed product distributions using Eq. (1). Oxidation product $\left(\mathrm{SqO}_{\mathrm{n}}\right)$ distributions computed for (a) unreacted squalane and at (b) $[\mathrm{OH}] \mathrm{t}=1.9 \times 10^{12}$ molec. $\mathrm{cm}^{-3} \mathrm{~s}$ and $(\mathrm{c})[\mathrm{OH}] \mathrm{t}=$ $5.5 \times 10^{12}$ molec. $\mathrm{cm}^{-3}$ s. (d) Volatilization operator, expressed as $1-\beta(\mathrm{n})$ as a function of product number, $n$. For $n=0-2,1-\beta(n)=1$, indicating that all of the $C, H$ and $O$ atoms associated with these generations remain in the aerosol phase and fully contribute to the average mass and elemental composition. For $\mathrm{n}>3$ there is an increasing probability that the elemental composition of these reaction products volatilize as gas phase molecules.

Figure 3: (a) Measured (०) $\mathrm{H} / \mathrm{C}$ vs. $\mathrm{O} / \mathrm{C}$ ratio in a Van Krevelen diagram compared with model calculations (solid line). The arrows indicate where the reaction begins and ends. (b) Measured (symbols) and computed (solid lines) changes density and volume normalized to unreacted squalane as a function of $\mathrm{OH}$ exposure. The data was originally reported in Kroll et al. ${ }^{10}$

Figure 4: Evolution of measured aerosol mass (panel a), and $\mathrm{O} / \mathrm{C}$ ratio (panel b) with $\mathrm{OH}$ exposure. The experimental data shown here were originally reported in Kroll et al. ${ }^{10}$ The dashed lines in (a) and (b) are predictions from Eq. (1) assuming no volatilization. The solid lines in (a) 
and (b) are model calculations including volatilization (see text). The dotted line in (b) shows predictions of the $\mathrm{O} / \mathrm{C}$ ratio of the gas phase products of volatilization.

Figure 5: Computed average aerosol mass (solid line) normalized to unreacted squalane as a function of $\mathrm{OH}$ exposure. Shaded regions show how the contribution of various product generations to the average aerosol mass change over the course of the reaction

Figure 6: Measured average numbers of $\mathrm{C}, \mathrm{O}$, and $\mathrm{H}$ atoms in the aerosol as a function of $\mathrm{OH}$ exposure. This data was originally reported in Kroll et al. ${ }^{10}$ Solid lines are model calculations (see text).

Figure 7: (a) Computed average number of carbon atoms (solid line) as a function of $\mathrm{OH}$ exposure. The contribution from groupings of product generations are shown as shaded regions. (b) Computed average number of oxygen atoms (solid line) as a function of $\mathrm{OH}$ exposure. The contribution from groupings of product generations are shown as shaded regions.

Figure 8: Heterogeneous oxidation trajectory measured $(\circ)$ for squalane by plotting the net number of oxygen atoms added to the particle as a function of the amount of carbon lost during the reaction, as reported in Kroll et al. ${ }^{10}$ Solid lines show results from the model calculations. Labels (i-iii) represent distinction regions of the reaction shown as idealized vectors in Fig. 9.

Figure 9: Idealized heterogeneous oxidation trajectories shown as individual vectors that might describe the various stages of organic aerosol oxidation. These idealized vectors are intended to 
show the competition between functionalization and fragmentation in the heterogeneous oxidation reaction.

Figure 10: A $10.5 \mathrm{eV}$ photoionization aerosol mass spectrum of $\mathrm{OH}$ oxidized bis(2-ethylhexyl) sebacate (BES) aerosol. Oxidation products are labeled as $\mathrm{BESO}_{\mathrm{n}}$ where $\mathrm{n}$ corresponds to the number of oxygenated functional groups in each product.

Figure 11: (a-d) The measured ( $(\circ)$ kinetic evolution of BES oxidation products $\left(\mathrm{BESO}_{\mathrm{n}}\right)$ as a function of $\mathrm{OH}$ exposure $([\mathrm{OH}] \mathrm{t})$. Each oxidation product is labeled according to the number $(\mathrm{n})$ of oxygenated function groups. For unreacted BES $n=0$. Solid lines are model calculations.

Figure 12: Evolution of average aerosol mass, density and volume (symbols) with $\mathrm{OH}$ exposure measured by George et al. ${ }^{20}$ Aerosol mass, density and volume are normalized to pure BES, before reaction. Lines are model calculations.

Figure 13: Measured ( $\mathrm{O}$ ) average $\mathrm{O} / \mathrm{C}$ ratio as a function of $\mathrm{OH}$ exposure reported by Lambe et al. ${ }^{29}$ To facilitate the comparison with model predictions (solid line) the $\mathrm{O} / \mathrm{C}$ ratio measurements have been offset by +0.1138 to give the correct atomic composition of unreacted $\mathrm{BES}(\mathrm{O} / \mathrm{C}=$ $0.154)$.

Figure 14: Measured (०) H/C vs. O/C for the $\mathrm{OH}$ oxidation of BES reported in Lambe et al. ${ }^{29}$ The solid line is the model calculation. 
Figure 15: Volatilization operator $\beta$ (Eq. (4)) expressed as a function of (a) $\mathrm{O} / \mathrm{C}$ ratio or (b) average change in oxidation state $\Delta \overline{O s_{C}}$ (relative to $\mathrm{n}=0$ ) of each product generation for squalane ( $\square)$ and BES (०). See text for details. 

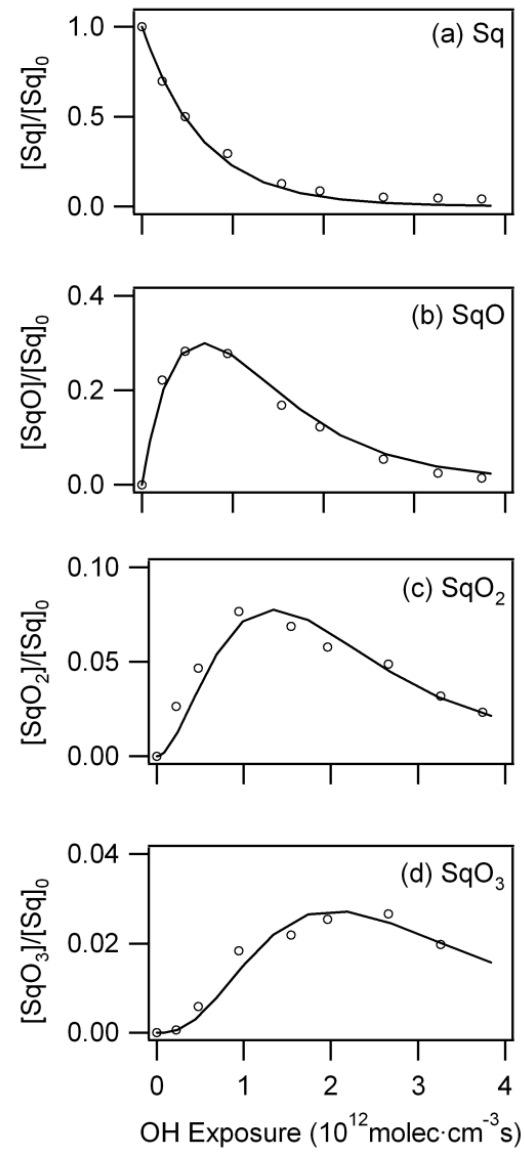

Figure 1 

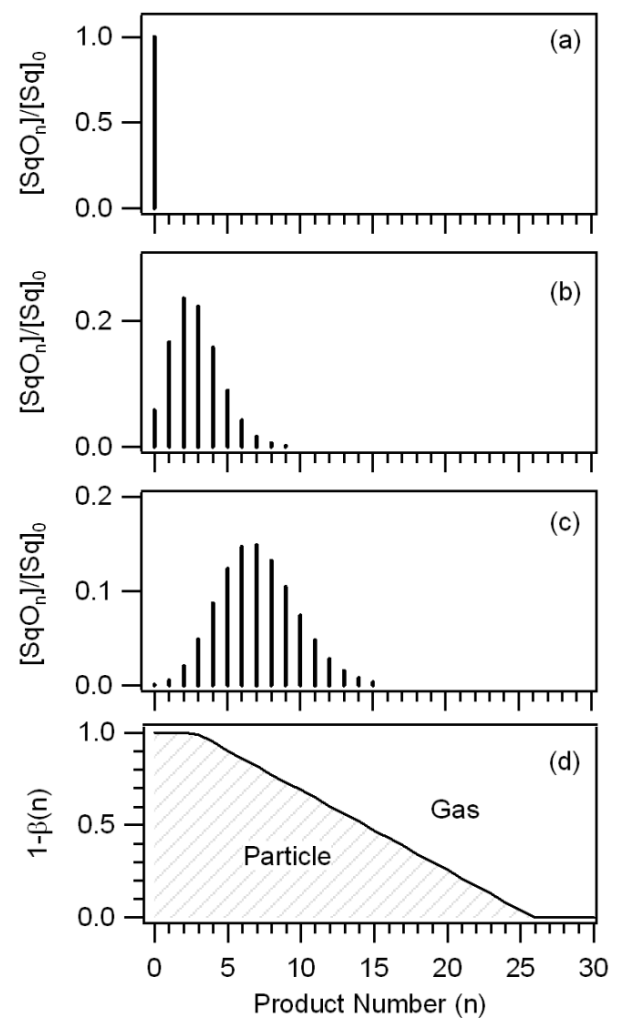

Figure 2 

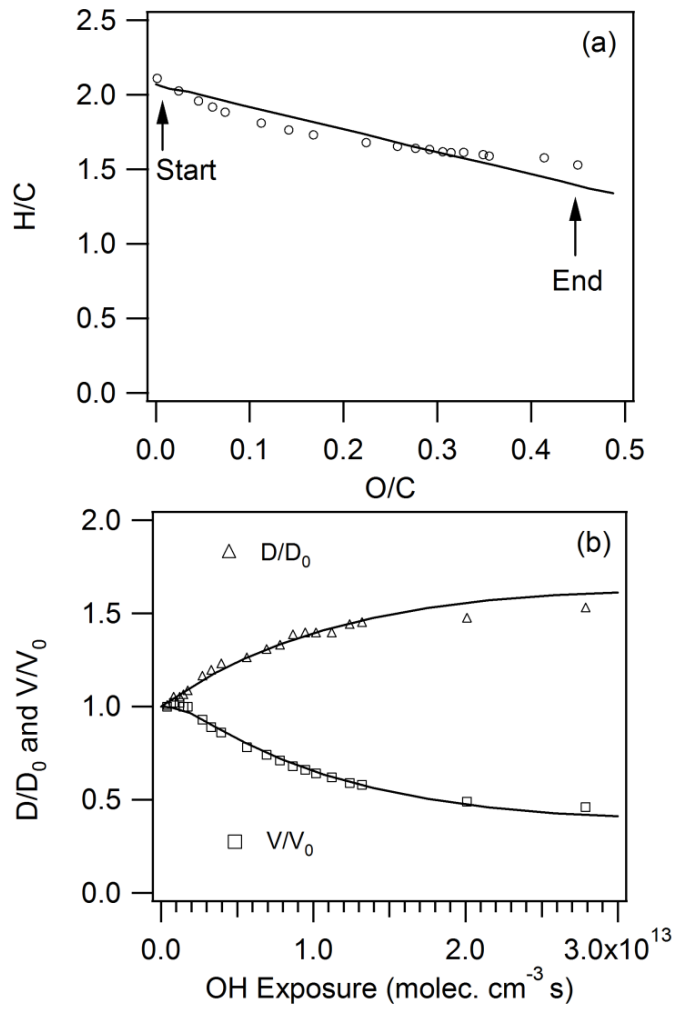

Figure 3 

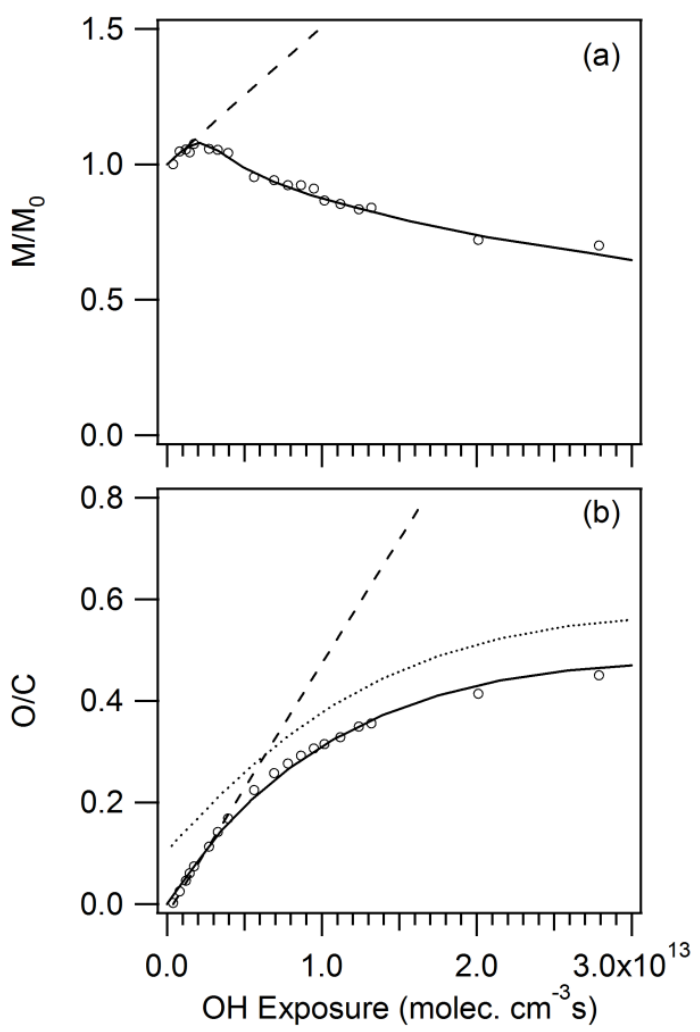

Figure 4 


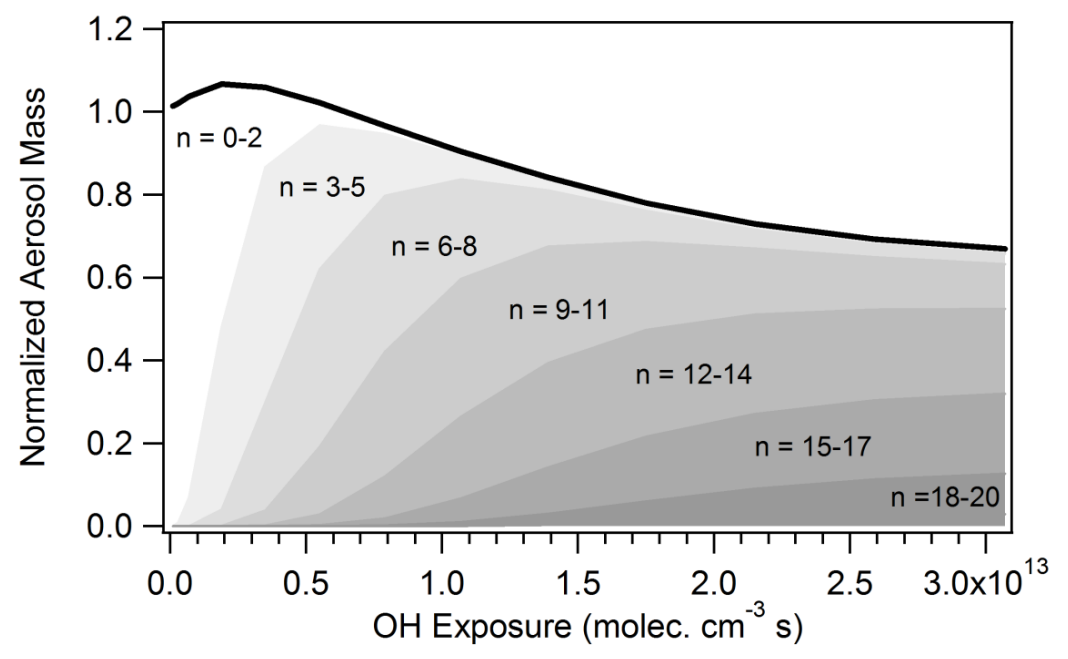

Figure 5 


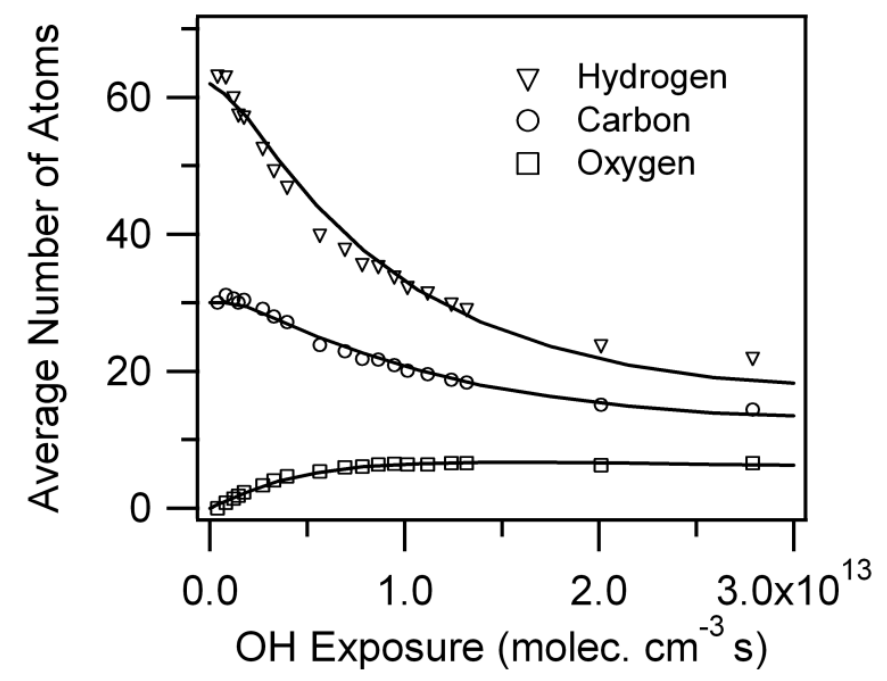

Figure 6 

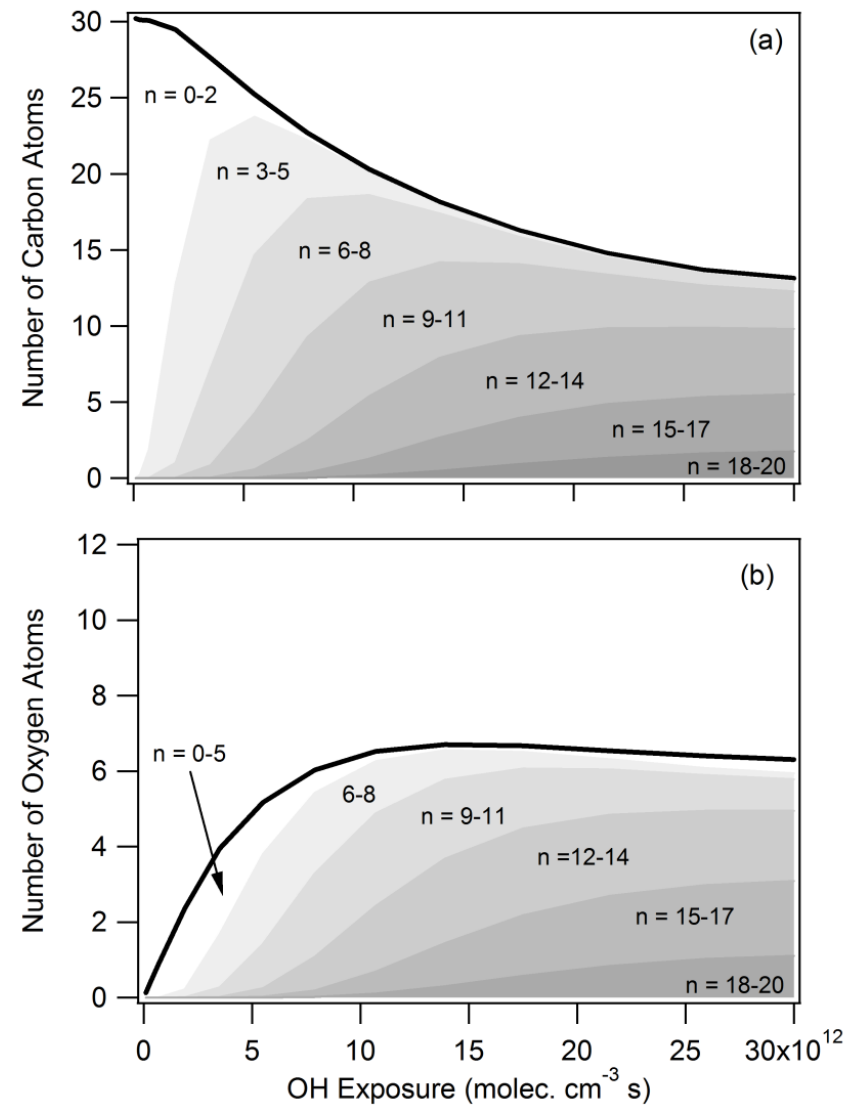

Figure 7 


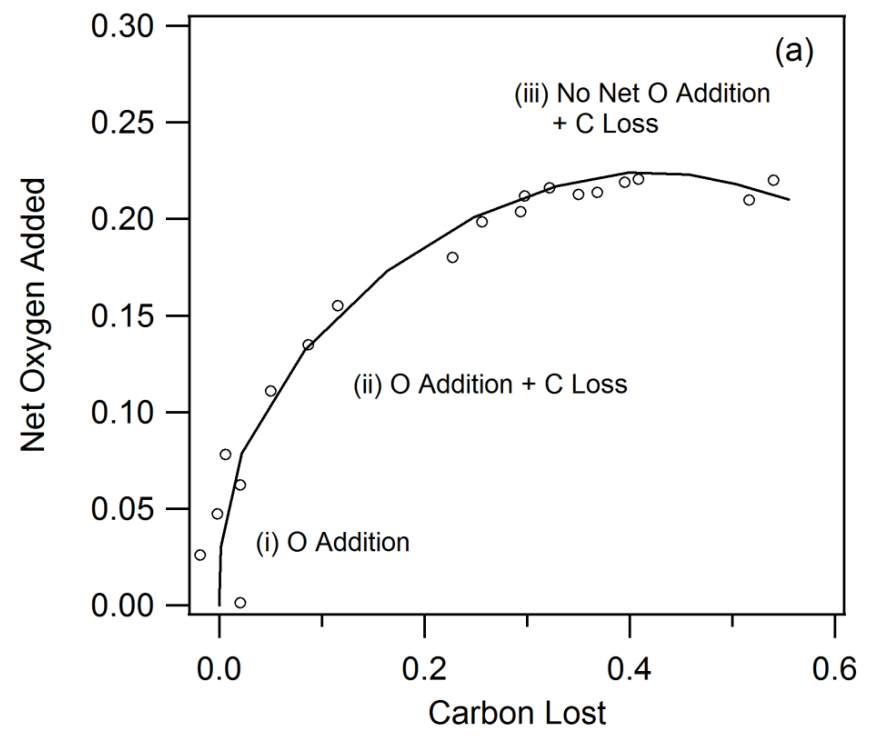

Figure 8 


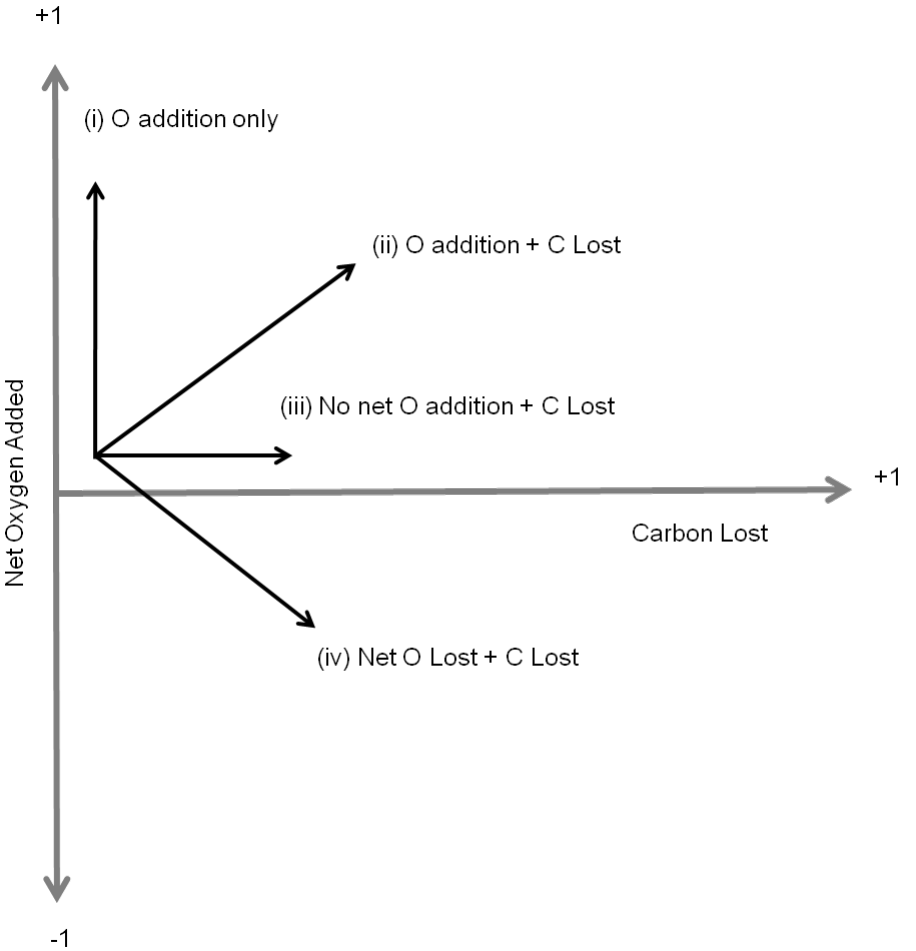

Figure 9 


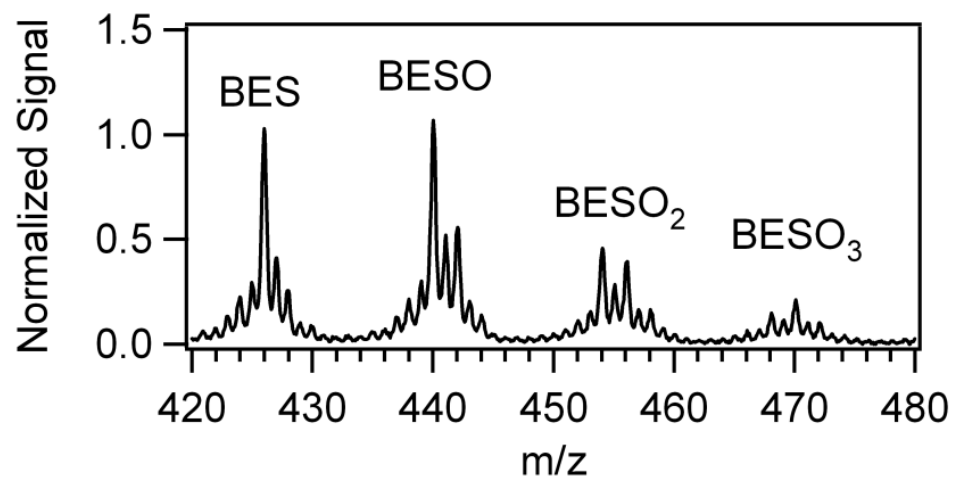

Figure 10 

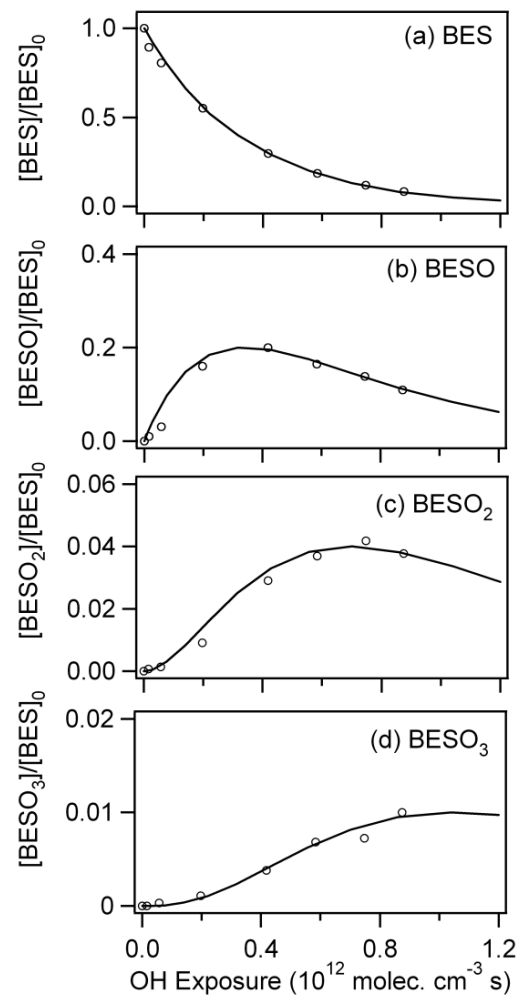

Figure 11 


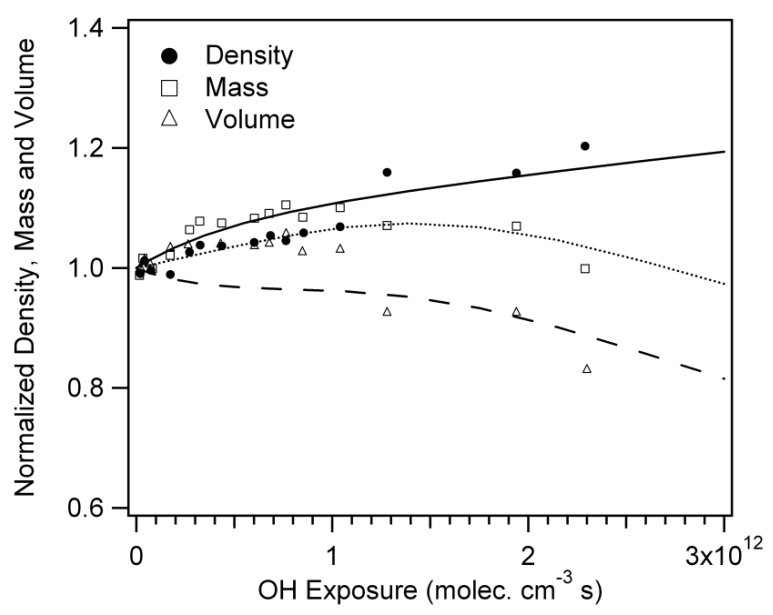

Figure 12 


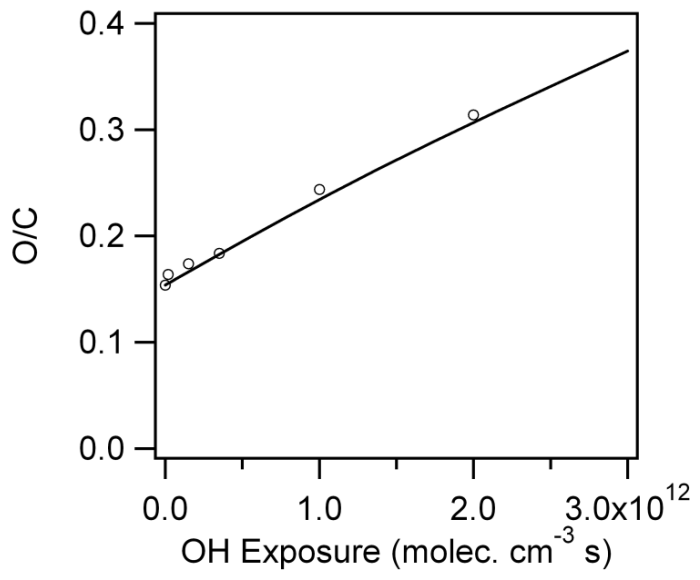

Figure 13 


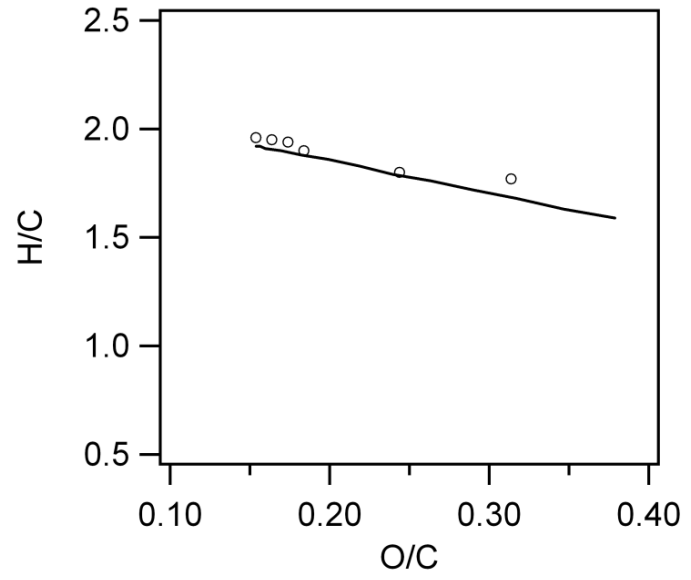

Figure 14 

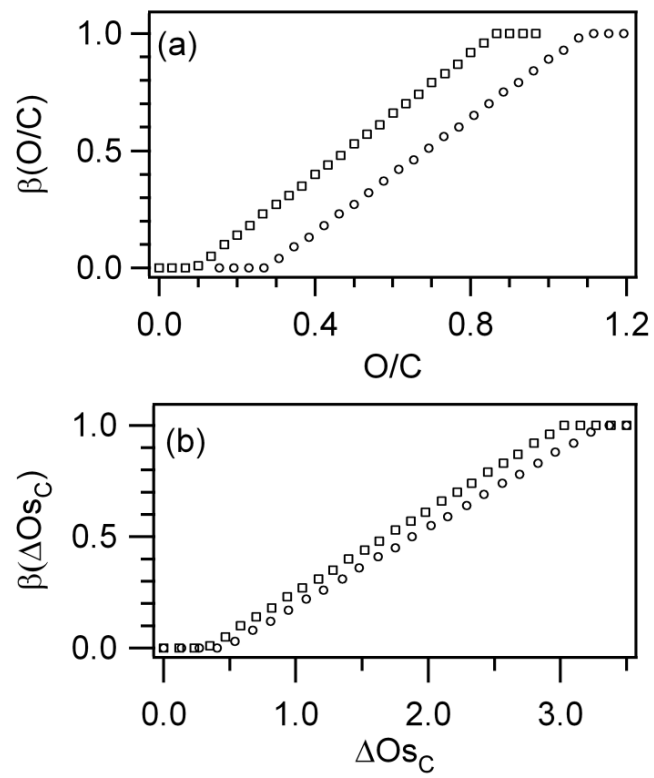

Figure 15 
This document was prepared as an account of work sponsored by the United States Government. While this document is believed to contain correct information, neither the United States Government nor any agency thereof, nor the Regents of the University of California, nor any of their employees, makes any warranty, express or implied, or assumes any legal responsibility for the accuracy, completeness, or usefulness of any information, apparatus, product, or process disclosed, or represents that its use would not infringe privately owned rights. Reference herein to any specific commercial product, process, or service by its trade name, trademark, manufacturer, or otherwise, does not necessarily constitute or imply its endorsement, recommendation, or favoring by the United States Government or any agency thereof, or the Regents of the University of California. The views and opinions of authors expressed herein do not necessarily state or reflect those of the United States Government or any agency thereof or the Regents of the University of California. 